\title{
Electrophysiological evidence for a distal lesion in alcoholic neuropathy
}

\author{
E. B. CASEY AND PAMELA M. LE QUESNE \\ From the Medical Research Council Toxicology Unit, Carshalton, Surrey, and \\ the Department of Neurological Studies, The Middlesex Hospital, London
}

SUMMARY Nerve conduction studies were carried out on 16 alcoholic subjects with minimal or no clinical evidence of peripheral neuropathy. Digital nerve action potentials recorded at the base of the finger were reduced in amplitude in five but the potential at the wrist was reduced in only one. $\mathrm{In}_{\mathrm{O}}$ two other patients, even though the values were within the control range, the ratio of the amplitude ${ }^{\infty}$ recorded from the finger and from the wrist was smaller than in control subjects. Thus, by recording both digital and wrist action potentials, abnormalities have been demonstrated in seven of 16 patients, whereas the wrist potential was abnormal in only one. Conduction velocity was slightlyo reduced in the fingers in three patients.

Abnormalities of both motor and sensory conduction have been demonstrated previously in patients with alcoholic peripheral neuropathy and also in alcoholic subjects without clinical evidence of peripheral nerve disease (Bergamini, Gandiglio, Fra, Bergamasco, Bram, and Mombelli, 1965; Mawdsley and Mayer, 1965; Walsh and McLeod, 1970; Blackstock, Rushworth, and Cath, 1972). In patients with neuropathy, Walsh and McLeod (1970) found a slight reduction in maximal motor conduction velocity. The amplitude of sensory nerve action potentials was reduced with only a slight increase in latency. Blackstock et al. (1972) investigated a less severely affected group of patients, only a few of whom had clinical evidence of neuropathy. Maximal velocity was normal in the clinically unaffected patients and slightly reduced in those with neuropathy. Abnormalities of the lower velocity motor fibres were, however, demonstrated in clinically unaffected as well as affected patients. The results of all these studies have shown that only minor changes in conduction velocity occur in alcoholic neuropathy.

Mawdsley and Mayer (1965) found that in some alcoholic patients velocity was reduced in the distal segments of the nerves in the arm when conduction proximally was normal. When a technique had been evolved for stimulating and recording from digital nerves in the fingerir (Casey, 1971; Casey and Le Quesne, 1972), decided that it might be useful to examine triso peripheral part of the nervous system in al $\frac{\pi}{\infty}-$ holic subjects.

\section{SUBJECTS}

Sixteen alcoholic patients, four females and 12 males, N whose ages ranged from 25 to 58 years (mean 43.9 years) were examined. All had been heavy drinkerso for many years and 14 were inpatients in an alcoholics unit undergoing psychiatric treatment. They had drunk at least a bottle of spirits a day and some hado drunk up to 3 gallons of beer or 4 litres of wine ande most had had several bouts of delirium tremens in $\overrightarrow{\overrightarrow{0}}$ the past. At the time of examination these patients 3 had been sober for periods ranging from one to eight weeks. During the time in hospital large doses of B vitamins had been given and a high calorie intake ensured. None of the patients had been treated witho disulphiram (Antabuse).

There were few neurological symptoms or signs in any of the patients. The motor system was normal ino all patients except one (B.H.) who had mild bilaterak foot drop. Tendon reflexes were present in all, although in six the ankle jerks could be obtained onlys on reinforcement. Thirteen had a past history of mild? intermittent paraesthesiae and numbness in the fingers and toes. Three of them had slight reduction of superficial sensation in the digits at the time of 
TABLE 1

SENSORY NERVE CONDUCTION IN ALCOHOLIC PATIENTS

\begin{tabular}{|c|c|c|c|c|c|c|c|c|}
\hline \multirow[b]{2}{*}{ Name } & \multirow[b]{2}{*}{ Sex } & \multirow[b]{2}{*}{$\begin{array}{l}\text { Age } \\
(y r)\end{array}$} & \multirow[b]{2}{*}{$\begin{array}{l}\text { Sensation } \\
\text { in fingers }\end{array}$} & \multicolumn{3}{|c|}{ Digital potential } & \multicolumn{2}{|c|}{ Wrist potential } \\
\hline & & & & $\begin{array}{c}\text { Amplitude } \\
(\mu V)\end{array}$ & $\begin{array}{r}\text { Onset } \\
\text { velocity } \\
(\mathrm{m} / \mathrm{sec})\end{array}$ & $\begin{array}{l}\text { Peak } \\
\text { velocity } \\
(\mathrm{m} / \mathrm{sec})\end{array}$ & $\begin{array}{c}\text { Amplitude } \\
(\mu V)\end{array}$ & $\begin{array}{c}\text { Peak } \\
\text { velocity } \\
(\mathrm{m} / \mathrm{sec})\end{array}$ \\
\hline B.H. & $\mathbf{F}$ & 48 & Paraesthesiae & 6 & 47 & 31 & 9 & 39 \\
\hline F.B. & $\mathbf{M}$ & 36 & Reduced & 16 & 61 & 40 & 24 & 50 \\
\hline D.D. & $\mathbf{M}$ & 27 & Normal & 31 & 50 & 39 & 25 & 47 \\
\hline P.L. & $\mathbf{M}$ & 51 & Normal & 36 & 50 & 37 & 26 & 56 \\
\hline C.B. & $\mathrm{F}$ & 56 & Normal & 28 & 47 & 35 & 12 & 38 \\
\hline F.L. & $\mathbf{F}$ & 46 & Normal & 43 & 50 & 37 & 20 & 54 \\
\hline S.E. & $F$ & 53 & Normal & 38 & 54 & 34 & 29 & 48 \\
\hline B.M. & $\mathbf{M}$ & 33 & Reduced & 39 & 68 & 42 & 24 & 45 \\
\hline D.J. & $\mathbf{M}$ & 48 & Paraesthesiae & 31 & 54 & 38 & 40 & 43 \\
\hline H.L. & $\mathbf{M}$ & 58 & Paraesthesiae & 13 & 45 & 34 & 13 & 43 \\
\hline E.B. & $\mathbf{M}$ & 50 & Reduced & 13 & 53 & 37 & 6 & 42 \\
\hline P.M. & $\mathbf{M}$ & 38 & Normal & 15 & 60 & 43 & 16 & 49 \\
\hline C.S. & $\mathbf{M}$ & 47 & Normal & 25 & 50 & 37 & 11 & 50 \\
\hline J.C. & $\mathbf{M}$ & 25 & Normal & 30 & 50 & 40 & 20 & 54 \\
\hline E.P. & $\mathbf{M}$ & 43 & Normal & 32 & 50 & 37 & 26 & 47 \\
\hline G.O. & $\mathbf{M}$ & 43 & Normal & 18 & 57 & 42 & 22 & 40 \\
\hline Mean (SD) & & $43 \cdot 9$ & & $25 \cdot 9(11 \cdot 1)$ & $52.9(6.0)$ & $37 \cdot 7(3 \cdot 3)$ & $20 \cdot 2(8 \cdot 7)$ & $46 \cdot 6(5 \cdot 5)$ \\
\hline \multirow{2}{*}{\multicolumn{2}{|c|}{$\begin{array}{l}\text { Controls } \\
\text { Mean (SD) } \\
\text { Range }\end{array}$}} & $51 \cdot 0$ & & $33.6(10.6)$ & $54 \cdot 8(7 \cdot 3)$ & $39.9(3.3)$ & $19 \cdot 8(6 \cdot 7)$ & $46.4(3.6)$ \\
\hline & & $30-75$ & & $18-56$ & $45-68$ & $35-46$ & 9-36 & $38-53$ \\
\hline
\end{tabular}

examination. Sensation was normal in the remaining patients although three still complained of mild paraesthesia. Details of individual patients are shown in Table 1.

\section{ELECTROPHYSIOLOGICAL METHODS}

In all patients nerve action potentials were recorded from the digital nerves at the base of the middle finger after stimulation distally (digital potential) and from the median nerve at the wrist after stimulation at the base of the middle finger (wrist potential). The technique for recording digital potentials from the base of the finger has been described by Casey and Le Quesne (1972). A battery-powered stimulator with a high degree of isolation from the recording apparatus was used. The skin temperature at the tip of the finger was always at least $35^{\circ} \mathrm{C}$. The wrist potential was recorded through saddle electrodes as described by Dawson (1956). The recording apparatus was a Medelec SDC3 with AVM 3B/1 averager. Peak to peak amplitude of the nerve potentials was measured. For the finger potential conduction velocity was calculated from latency to the onset and peak of the negative deflection ('onset velocity' and 'peak velocity'), and for the wrist potential from latency to the peak of the main deflection. The results in the alcoholic subjects have been compared with the control values obtained by Casey and Le Quesne (1972) in 22 healthy subjects aged 30 to 75 years.
Motor nerve conduction was studied in the lateral popliteal nerve. Supramaximal stimuli were applied to the nerve at the ankle and the head of the fibula. The skin temperature of the lower limb was never less than $30^{\circ} \mathrm{C}$. The muscle response was recorded through electrodes of the Dawson saddle type, one of which was placed over the muscle belly of extensor digitorum brevis and the other $4 \mathrm{~cm}$ distally, over the tendon. The electrode position was adjusted until the largest response to nerve stimulation was seen. The amplitude of the evoked muscle potential was estimated from the height of the negative deflection above the base line. Maximal motor conduction velocity was calculated from the difference in latency of the two responses. The control values obtained by Catton, Harrison, Fullerton, and Kazantzis (1970) in 17 healthy subjects were used for comparison. It should be noted, however, that the mean age of the control subjects (26.8 years) was less than that of the patients ( 43.9 years).

\section{RESULTS}

NERVE ACTION POTENTIALS The amplitude of the digital and wrist potentials in the 16 patients are shown in Table 1 and Figs 1 and 2. The amplitude of the digital potentials ranged from 6-43 $\mu \mathrm{V}$ and was below the control range in five patients. The amplitude of the wrist potential ranged from $6-40 \mu \mathrm{V}$ and was abnormal in only 
one patient. The mean amplitude of the digital potential was reduced compared with the control value, whereas there was no difference in the mean amplitude of the wrist potential in the alcoholic and control subjects (Fig. 1).

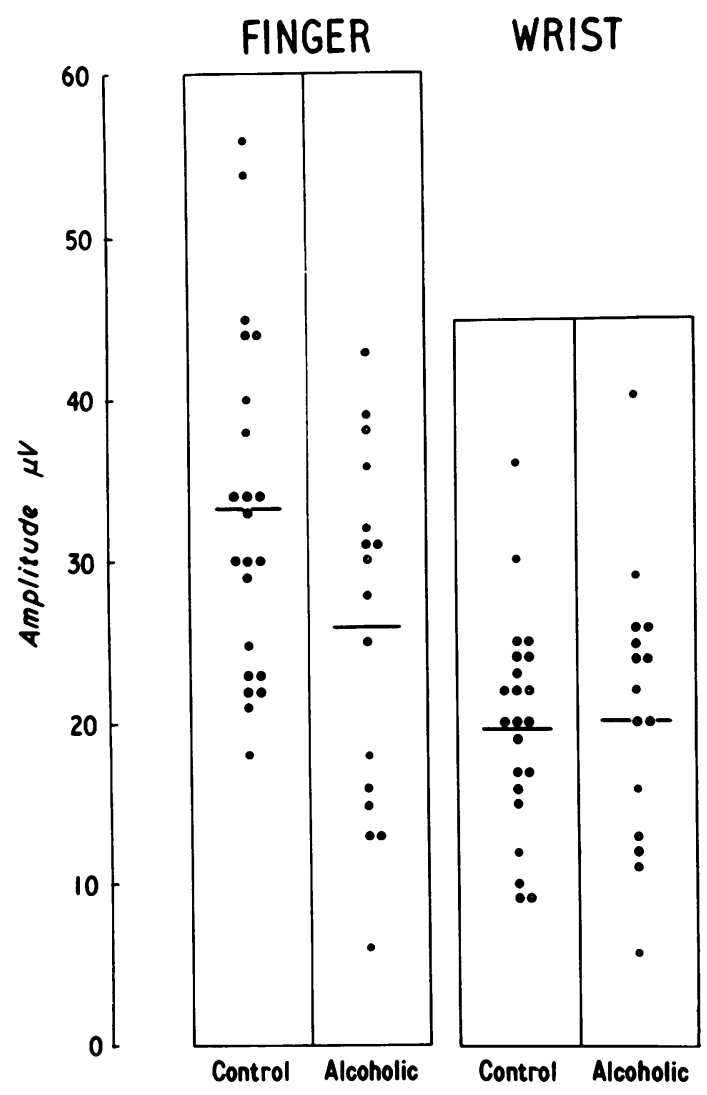

FIG. 1. Comparison of amplitude of finger and wrist sensory action potentials in control subjects and alcoholic patients.

The relation between the digital and wrist potentials is shown in Fig. 2. In control subjects the digital potential was always larger (approximately one-and-a-half times) than the wrist potential (Casey and Le Quesne, 1972). In two of the alcoholic subjects (D.J. and S.O.) even though both digital and wrist potentials were within control limits, the digital potential was smaller than the wrist potential. Thus, as a result of measuring both digital and wrist potentials, abnormalities have been demonstrated in seven of the 16 alcoholic subjects, whereas the wrist potential itself was abnormal in only one instance.

Mean conduction velocity in the digital nerves was only slightly slower in alcoholic than in control subjects, and there was no difference in the mean velocity for the wrist potential (Table 1 and Fig. 3). Only three values for peak digital conduction velocity were slightly below the of control range and all values for onset digital $\tau$ velocity and for wrist velocity were within the control range.

The records obtained from one subject (B.H.) $\stackrel{\mathbb{\Phi}}{\circ}$ are shown in Fig. 4 compared with those from a is control subject. The marked reduction in ampli- $\vec{\circ}$ tude of the digital potential can be seen with little difference in latency or amplitude of the wrist potentials.

MOTOR CONDUCTION STUDIES Motor nerve conduction studies were carried out in the laterat $r$ popliteal nerve of all but one of the alcoholio $N$ patients on the same day as the finger and wris potentials were recorded. Table 2 and Fig. show the results for individual subjects and the mean values for the whole group. The amplitude of of the evoked potentials obtained on stimulatiog at the ankle ranged from $2 \cdot 3$ to $12.8 \mathrm{mV}$ (mea $6.2 \mathrm{mV}$; SD 2.8) and that obtained on stimula tion at the head of the fibula from 2.2 to $11.9 \mathrm{mV}$ (mean $5.7 \mathrm{mV}$; SD 2.8). Both of these mean values are less than for the controls, but the difference is not significant. (For the amplitude after ankle stimulation $t=1 \cdot 65, \mathrm{P}>0 \cdot 1)$.

When the amplitude of the potential obtained from stimulation at the head of the fibula was expressed as a percentage of that obtained on stimulation at the ankle, values from 81 to $100 \%$ were obtained. Although only one value was below the range obtained by Catton et al. (1970) for control subjects, the difference between the means was significant $(t=3 \cdot 35, \mathrm{P}<0 \cdot 005)$.

The maximal motor conduction velocity in the $\delta$ lateral popliteal nerve ranged from 43 to $58 \mathrm{~m} / \mathrm{sec}$ and as may be seen from Table 2 these values 음 are similar to the control values found by $\rightarrow$ Catton et al. (1970). The difference between the means was not significant $(t=1.49, \mathrm{P}>0 \cdot 1)$. N Thus, no abnormality of muscle action potential 

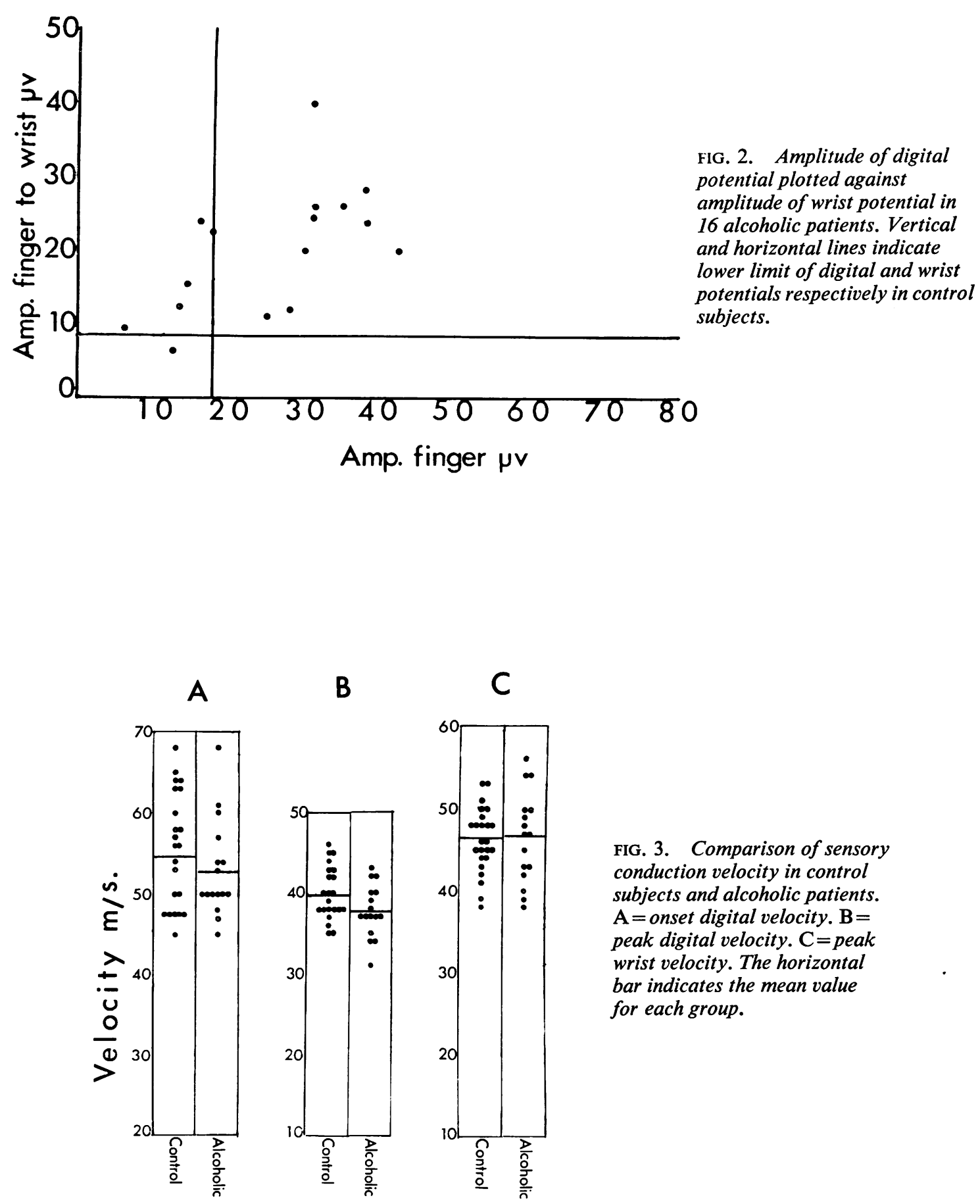

FIG. 3. Comparison of sensory conduction velocity in control subjects and alcoholic patients. $\mathrm{A}=$ onset digital velocity. $\mathrm{B}=$ peak digital velocity. $\mathrm{C}=$ peak wrist velocity. The horizontal bar indicates the mean value for each group. 
Finger A P

Wrist A P

Control

Subject

Alcoholic

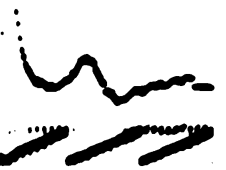

FIG. 4. Digital and wrist

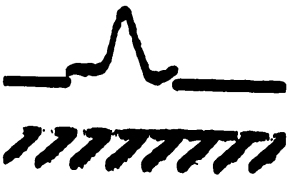

$\longmapsto$

Im.sec

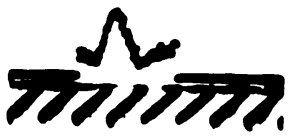
and a patient with alcoholic peripheral neuropathy.

TABLE 2

MOTOR NERVE CONDUCTION IN ALCOHOLIC PATIENTS

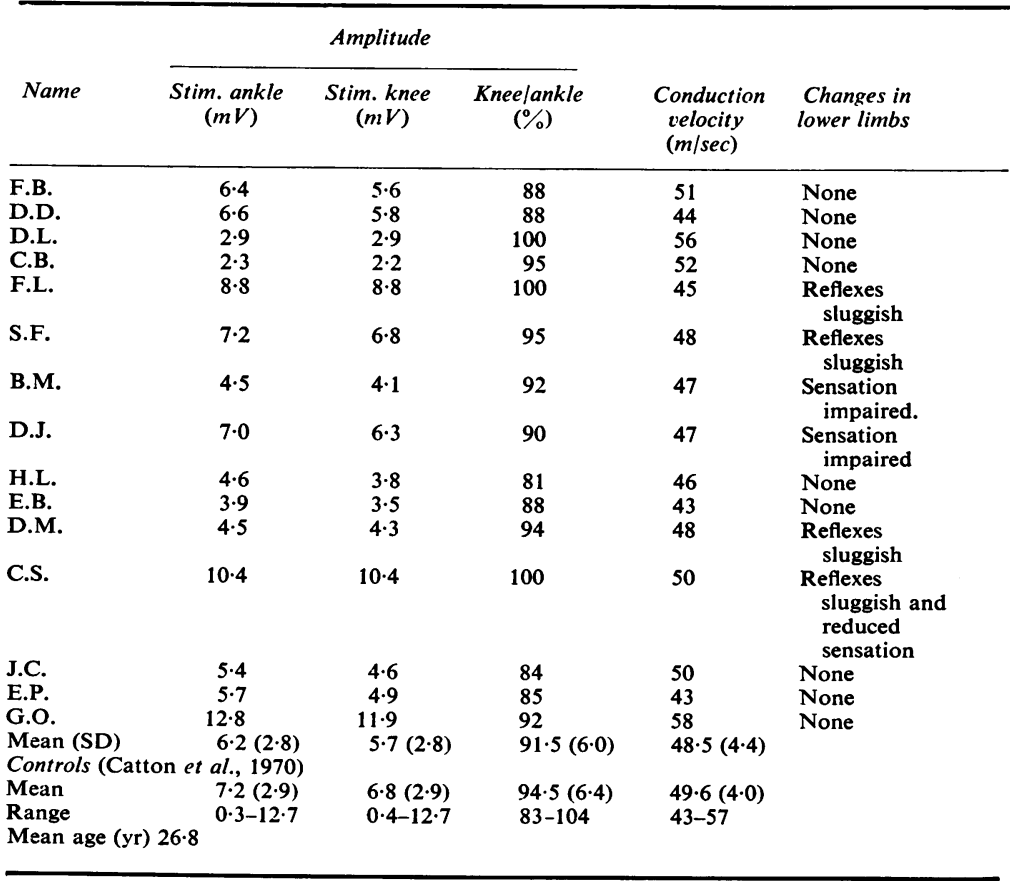



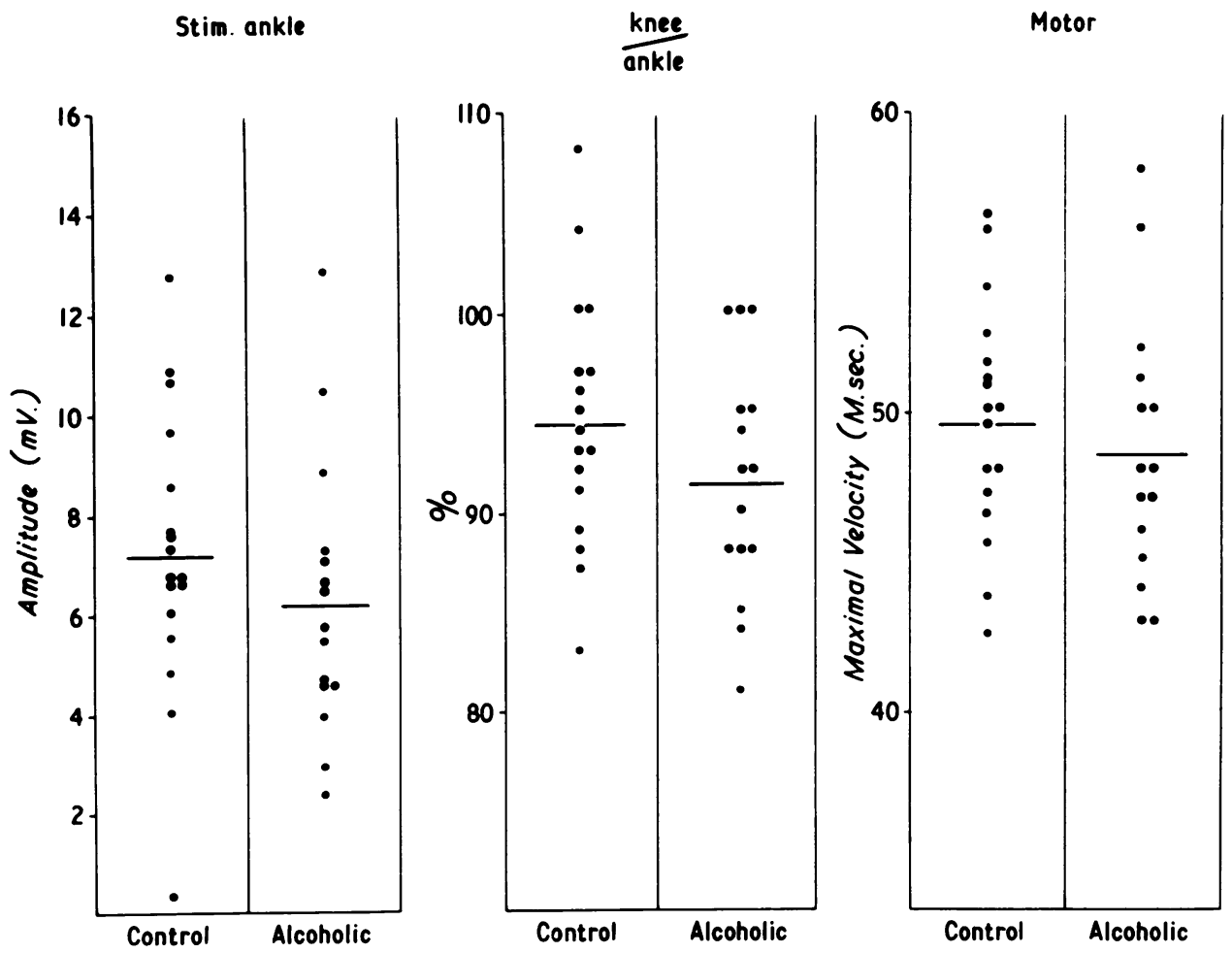

FIG. 5. Motor conduction in lateral popliteal nerve in control subjects and alcoholic patients.

amplitude or of maximal motor conduction velocity has been demonstrated. The slight reduction in ratio of amplitudes after stimulation at knee and ankle might indicate some dispersion of the volley from the knee. However, it must be noted that the age of the subjects studied by Catton et al. (1970) was less. Age has less influence on conduction in motor than sensory nerve fibres (LaFratta and Canestrari, 1966) but nevertheless there must be some reservation as to the significance of these findings.

\section{DISCUSSION}

The present study has shown that in a group of alcoholic patients without or with minimal clinical evidence of peripheral neuropathy, sensory nerve action potentials may be reduced in amplitude in the most distal parts of the nerves in the arm at a time when proximal segments are normal. Conduction velocity distally was only slightly reduced in a few patients, but was normal in most. In most other studies of conduction velocity in alcoholic neuropathy changes have been slight (Coërs and Hildebrand, 1965; Walsh and McLeod, 1970; Blackstock et al., 1972).

Reduction in amplitude of nerve action potentials with preservation of normal conduction velocity suggests that axonal degeneration is occurring. Walsh and McLeod (1970) found histological changes of axonal degeneration in sural nerves from 11 patients with alcoholic neuropathy. A common pattern of axonal degeneration is that changes start at and spread from the distal ends of the fibres (Cavanagh, 1964). The pattern of abnormality demonstrated electrophysiologically in alcoholic neuropathy suggests that nerve fibres are dying back in this way.

Walsh and McLeod (1970) found many regenerating fibres in the sural nerves from 
patients with chronic neuropathy, even when they continued to take alcohol. The situation is comparable with that in chronic acrylamide intoxication, when a dying back neuropathy occurs. Fullerton and Barnes (1966) in rats and Fullerton (1969) in man found evidence of regenerating fibres while intoxication continued. It thus seems probable that when only the distal parts of the nerves degenerate, regeneration occurs relatively easily.

There is increasing evidence that the distinction between axonal degeneration and segmental demyelination is rarely absolute (Thomas, 1971). Although one type of pathological change predominates, a mixed type of pathology may be found in some instances. This may be true in a few cases of alcoholic neuropathy. Mawdsley and Mayer (1965), for example, found considerable slowing of conduction in a few of their alcoholic patients. In one patient motor conduction velocity in the leg was as low as $22 \mathrm{~m} /$ sec. They suggested that segmental demyelination, with associated reduction in velocity, might occur at an early stage of the disease, as originally suggested by Denny-Brown (1958).

The slight reduction in maximal conduction velocity in both motor and sensory nerves in alcoholic neuropathy and in other neuropathies in which axonal degeneration is found could be explained by failure of conduction in the most rapidly conducting fibres, conduction continuing normally in the slower fibres. Hopkins and Gilliatt (1971) produced evidence that this is the explanation for the reduction in maximal velocity in acrylamide neuropathy in baboons. However, it is not clear whether the same explanation applies in other types of axonal degneration. The wider than normal range of motor conduction velocity found by Blackstock et al. (1972) and the evidence for a slight degree of dispersion of the motor nerve volley in the present study suggest that there is some disturbance of the conduction mechanism, at least in the slower conducting motor fibres in alcoholic neuropathy. However, there is no evidence as to whether this is due to segmental demyelination of a few fibres as already discussed, or whether there is some other conduction disturbance.
We would like to thank Dr. C. Salter for allowing us to examine his patients. Eoin B. Casey is very grateful to University College, Cork, Eire, for the award of an Ainsworth Studentship.

\section{REFERENCES}

Bergamini, L., Gandiglio, G., Fra, L., Bergamasco, B., Bram, S., and Mombelli, A. M. (1965). Alterazioni della conduzione nervosa sensitiva e motoria in alcoolisti cronici privi di segni clinici di neuropatia periferica. Rivista di Patologia Nervosa et Mentale, 86, 31-49.

Blackstock, E., Rushworth, G., and Cath, D. (1972). Electrophysiological studies in alcoholism. Journal of Neurology, Neurosurgery, and Psychiatry, 35, 326-334.

Casey, E. B. (1971). Digital nerve sensory action potentials in health and in peripheral nerve disorders with a clinical and electrophysiological study of vincristine neurotoxicity. M.D. Thesis. National University of Ireland (Cork).

Casey, E. B., and Le Quesne, P. M. (1972). Digital nerve action potentials in healthy subjects, and in carpal tunnel and diabetic patients. Journal of Neurology, Neurosurgery, and Psychiatry, 35, 612-623.

Catton, M. J., Harrison, M. J. G., Fullerton, P. M., and Kazantzis, G. (1970). Subclinical neuropathy in lead workers. British Medical Journal, 2, 80-82.

Cavanagh, J. B. (1964). The significance of the 'dying back' process in experimental and human neurological disease. International Review of Experimental Pathology, 3, 219-267o

Coërs, C., and Hildebrand, J. (1965). Latent neuropathy in diabetes and alcoholism. Electromyographic and histo logical study. Neurology (Minneap.), 15, 19-38.

Dawson, G. D. (1956). The relative excitability and conduc tion velocity of sensory and motor nerve fibres in $\operatorname{man}$ Journal of Physiology, 131, 436-451.

Denny-Brown, D. (1958). The neurological aspects of thiamine deficiency. Federation Proceedings, 17 (Suppto No. 2), 35-39.

Fullerton, P. M. (1969). Electrophysiological and histological observations on peripheral nerves in acrylamide poisoning in man. Journal of Neurology, Neurosurgery, and Psychiatry, 32, 186-192.

Fullerton, P. M., and Barnes, J. M. (1966). Peripheral neuropathy in rats produced by acrylamide. British Journal of Industrial Medicine, 23, 210-221.

Hopkins, A. P., and Gilliatt, R. W. (1971). Motor and sensory nerve conduction velocity in the baboon: normal values and changes during acrylamide neuropathy. Journal of Neurology, Neurosurgery, and Psychiatry, 34, 415-426.

LaFratta, C. W., and Canestrari, R. E. (1966). A comparison of sensory and motor nerve conduction velocities as related to age. Archives of Physical Medicine, 47, 286-290.

Mawdsley, C., and Mayer, R. F. (1965). Nerve conduction in alcoholic polyneuropathy. Brain, 88, 335-356.

Thomas, P. K. (1971). The morphological basis for alterations in nerve conduction in peripheral neuropathy. Proceedings of the Royal Society of Medicine, 64, 295-298.

Walsh, J. C., and McLeod, J. G. (1970). Alcoholic neuropathy. An electrophysiological and histological study. Journal of Neurological Science, 10, 457-469. 